\title{
Head Position Comparison between Students with Normal Hearing and Students with Sensorineural Hearing Loss
}

\author{
Renato de Souza Melo ${ }^{1}$ Polyanna Waleska Amorim da Silva ${ }^{2}$ Robson Arruda Souza ${ }^{3}$ \\ Maria Cristina Falcão Raposo ${ }^{4}$ Karla Mônica Ferraz ${ }^{5}$
}

1 Universidade Federal de Pernambuco (UFPE), Recife/PE, Brasil

2 Faculdade Integrada do Recife (FIR), Recife/PE, Brasil

${ }^{3}$ Associação Caruaruense de Ensino Superior (ASCES), Caruaru/PE, Brasil

${ }^{4}$ Department of Statistics, Universidade Federal de Pernambuco (UFPE), Recife/PE, Brasil

${ }^{5}$ Department of Physical Therapy, Universidade Federal de

Pernambuco (UFPE), Recife/PE, Brasil

Int Arch Otorhinolaryngol 2013;17:363-369.

\author{
Address for correspondence Renato de Souza Melo, MD, Rua Avelino \\ Cândido, 32, Salgado, Caruaru/PE, CEP 55018-070, Brazil \\ (e-mail: renatomelo10@hotmail.com).
}

\begin{abstract}
Keywords

- vestibular diseases

- deafness

- posture

- postural balance

- ear

- inner

Introduction Head sense position is coordinated by sensory activity of the vestibular system, located in the inner ear. Children with sensorineural hearing loss may show changes in the vestibular system as a result of injury to the inner ear, which can alter the sense of head position in this population.

Aim Analyze the head alignment in students with normal hearing and students with sensorineural hearing loss and compare the data between groups.

Methods This prospective cross-sectional study examined the head alignment of 96 students, 48 with normal hearing and 48 with sensorineural hearing loss, aged between 7 and 18 years. The analysis of head alignment occurred through postural assessment performed according to the criteria proposed by Kendall et al. For data analysis we used the chi-square test or Fisher exact test.

Results The students with hearing loss had a higher occurrence of changes in the alignment of the head than normally hearing students $(p<0.001)$. Forward head posture was the type of postural change observed most, occurring in greater proportion in children with hearing loss $(p<0.001)$, followed by the side slope head posture $(p<0.001)$.

Conclusion Children with sensorineural hearing loss showed more changes in the head posture compared with children with normal hearing.
\end{abstract}

\section{Introduction}

Posture can be defined as the position or attitude of the body available in static or harmonic arrangement of body parts in dynamic situations. ${ }^{1}$ Good posture is a result of the ability of the bones, ligaments, capsules, and muscle to bear the body upright, allowing a person to stay in one position for prolonged periods without discomfort and with low power consumption. $^{2}$

In the standard posture, the spine has normal curvatures, and the bones of the lower limbs are in perfect alignment for support of body weight. The neutral position of the pelvis leads to the proper alignment of the abdomen, trunk and lower limbs, thorax, and upper spine so that the function of the respiratory muscles is favored. The head is upright, received

March 3, 2013

accepted

May 19, 2013
Copyright $@ 2013$ by Thieme Publicações Dol http://dx.doi.org/ Ltda, Rio de Janeiro, Brazil $10.1055 / \mathrm{s}-0033-1351685$. ISSN 1809-9777. 
balanced, and aligned to minimize burden on the neck muscles that are responsible for their support and position. ${ }^{2}$

The sense of head position and hence the alignment expressed by body posture are influenced by information from the proprioceptive receptors located in the neck and the sensory information coming from the vestibular system. ${ }^{3}$ Situated in the inner ear, the vestibular-cochlear system features dual function: the cochlea is responsible for hearing and the vestibule for the regulation of balance and postural control. ${ }^{4}$

Due to the proximity of the anatomical structures responsible for auditory and vestibular function, it is common to find associated changes in both systems in the case of involvement of the inner ear ${ }^{5}$; thus it is believed that many children with hearing loss have vestibular problems concomitant with sensorineural hearing loss. ${ }^{6}$ In this sense, studies have shown that the hypoactivity of the vestibular system is a common finding during otoneurologic assessment in children with sensorineural hearing loss, ${ }^{7-9}$ altering the sensory information from the vestibular system.

If sensory information coming from the vestibular system is inaccurate or there is a failure in integrating it with the central nervous system, changes in head position can occur, resulting in a distorted reference of sense of the position of the head, neck, and possibly body posture. ${ }^{3}$

Given the above, children with sensorineural hearing loss appear have vestibular deficits concomitant with sensorineural hearing loss as a result of injury to the inner ear, ${ }^{10}$ and this can change the sense of the position of the head of the children, making them more susceptible to the changes in head posture compared with normally hearing students, justifying the completion of this study, which analyzed the alignment of the head of normally hearing students with sensorineural hearing loss and compared the distribution of changes in head posture between groups, considering genders and age groups in the sample and also the degree of hearing loss in the group of children with hearing loss.

\section{Methods}

This is a cross-sectional study, which was conducted between August and December 2012. To delimit the sample size of this study, a survey was conducted with the manager of the Center for Rehabilitation and Special Education Rotary to identify the number of children with sensorineural hearing loss enrolled of ages desired by the study and those who fit the criteria for inclusion and exclusion. This school aims to teach children and teens with special needs.

Thus, it was possible to pair 48 students regarding gender and age, because there was a predominance of one gender and some age groups, hampering the expansion of sample of this study. The same amount of students was set to form the normally hearing group and the pairing between the two groups. Thus, 96 students, aged between 7 and 18 years, participated in this study, 48 with normal hearing and 48 with sensorineural hearing loss.

The students were recruited by a convenience sample, matched for gender and age, and selected by a draw conducted by their teachers, who were not aware of the charac- teristics of this study. The draws were held in their classroom, in front of all students and of researchers of this study.

The normally hearing students were recruited from the School Duque de Caxias, geared to the public with normal hearing, and students with hearing loss were recruited from the Center for Rehabilitation and Special Education Rotary. Both are state schools, have similar profiles, and are located in the municipality of Caruaru/PE.

The volunteers were divided into two groups: a normally hearing group and a sensorineural hearing loss group. The normally hearing group was composed of 48 students, 24 males and 24 females, with two representatives of both genders by age. Exclusion criteria for this group included the presence of any disability (neurological, hearing, visual, mental), history of trauma in the head and neck, and lower limb discrepancy greater than 2 inches, obtained through measurement test real and apparent extent of the lower limbs, previously performed by evaluators.

The sensorineural hearing loss group, formed by 48 students, 24 males and 24 females, also contained two representatives of both genders by age. Exclusion criteria for this group were presence of any other associated disabilities, history of trauma in the head and neck, and lower limb discrepancy greater than 2 inches, obtained through tests measuring real and apparent length of the lower limbs, previously performed by the evaluators.

Inclusion criteria for both groups included regular enrollment in one of the schools collaborating with research, within the age group intended for the study, and submission of the term of consent duly signed by the parent or responsible of the volunteer, and exclusively for those with hearing loss, fluency in the Brazilian Sign Language (LIBRAS), submission of medical report of clinical diagnosis of sensorineural hearing loss, and audiometry performed in the last 6 months.

There was also a division between the groups of children with hearing loss, according to the degrees of hearing loss presented. The students were divided into two subgroups, one group of mild to moderate loss and the other, severe to profound loss. Students were stratified in this way due to many reports of audiometry already experienced within this diagnosis. It is worth noting that some students had different degrees of hearing loss from one ear to another; however, the differences always were mild to moderate or severe to profound.

For data confirmation of the inclusion and exclusion criteria of this study, we considered the information reported by parents of students during the interview with the researchers, together with data obtained in the student's transcript.

The procedures before testing and evaluation of head alignment were previously explained by researchers to normally hearing volunteers orally and volunteers with hearing loss through the LIBRAS by one of the researchers who interpreted LIBRAS.

For acquisition of the data posture, individually, each student was assessed on a flat surface, barefoot in a bathing suit (shorts for boys and bikinis and hair piled high on the 
head for girls), at a distance of $20 \mathrm{~cm}$ from a wall. As postural reference, we used the standard anatomical points proposed by Kendall et al, ${ }^{11}$ visualizing the volunteers in the following planes: coronal plane, anterior and posterior and sagittal plane, left and right.

These criteria allow assessment of the posture and identification of deviations in head posture, such as the forward, protrusion, tilted, and rotated side of head positions. The anatomical landmarks referenced and demarcated in this study were: glabella, gulp, mental protuberance, acromion, manubrium sternum, spinous process of $\mathrm{C} 7$ spinous process, and $\mathrm{T} 3$.

The postural assessment data were recorded on a standardized form containing the student ID, birth date, grade, school, and changes in head posture observed in each of the planes examined at the same moment by two physiotherapists, as suggested by Polly et al. ${ }^{12}$

After evaluating posture in the sensorineural hearing loss group, we collected data about the degree of hearing loss by audiometry brought by parents or guardians or in the student's records.

The data are expressed as percentage frequency and were analyzed using the chi-square test and Fisher exact test. The level of significance was set at $p<0.05$. For data analysis, we used the Software Statistical Package for Social Sciences (SPSS) version 18.0.

This study was approved by the Ethics Committee at the Hospital of the Restoration (CEP/HR) as the protocol number 1793.0.000.102-11, according to Resolution 196/96 of the National Health Council.

\section{Results}

In the present study, we evaluated head posture of 48 students with normal hearing and 48 students with sensorineural hearing loss; students had a mean age of $12.5 \pm 3.5$ years in each group, as shown in -Table $\mathbf{1}$.
The results showed a higher occurrence of changes in the head posture in the group of students with hearing loss compared with normally hearing students (normally hearing $20.8 \%$, hearing loss $75 \%, p<0.001$ ). According to the analysis of prevalence ratio, the occurrence of changes in head posture in children with hearing loss can be 3.26 times higher than in normally hearing students (confidence interval =1.95; 5.46), as shown in - Table 2.

Regarding the type of postural change, the forward position of the head was the most common abnormality in both groups, occurring in greater proportion in the students with hearing loss (normal hearing $14.6 \%$, hearing loss $52.1 \%$, $p<0.001$ ), which indicated a prevalence ratio of 2.17 times greater probability of presenting in students with hearing loss compared with normally hearing students in this sample (confidence interval $=1.49$; 3.16), shown in -Table 2 .

The inclination lateral head was the second postural change most frequently observed in both groups, affecting more students with hearing loss (normal hearing 6.25\%, hearing loss $50 \%, p<0.001$ ). The likelihood of developing this change was 2.56 times higher in students with hearing loss compared with students with normal hearing (confidence interval $=1.80 ; 3.62$ ), as shown in - Table 2. Moreover, the rotated laterally with protruding head posture, although most often observed in the group of children with hearing loss, showed no association with hearing loss, as shown in -Table 2.

According to the genres and changes in head posture, the results showed differences between groups (female: 20.8\% normal hearing, hearing loss $79.2 \%, p<0.001$; male: normal hearing $20.8 \%$, hearing loss $71.4 \%, p=0.001$ ). The same occurred with the forward head posture (female: normal hearing $12.6 \%$, hearing loss $54.6 \%, p=0.002$; male: normal hearing $16.7 \%$, hearing loss $50 \%, p=0.014$ ). The same results were found for lateral inclination of head (female: normal hearing $8.3 \%$, hearing loss $41.7 \%, p=0.008$; male: normal hearing $4.2 \%$, hearing loss $58.3 \%, p<0.001$; - Table 3 ).

Table 1 Characterization of the sample

\begin{tabular}{|c|c|c|c|c|c|}
\hline & \multicolumn{2}{|l|}{ Hearing } & \multicolumn{2}{|l|}{ Hearing loss } & \multirow[t]{2}{*}{$p$} \\
\hline & $\mathrm{n}$ & $\%$ & $\mathrm{n}$ & $\%$ & \\
\hline Volunteers & 48 & 100 & 48 & 100 & - \\
\hline \multicolumn{6}{|l|}{ Gender } \\
\hline Female & 24 & 50 & 24 & 50 & - \\
\hline Male & 24 & 50 & 24 & 50 & - \\
\hline Age (mean) & $12.5 \pm 3.5$ & 100 & $12.5 \pm 3.5$ & 100 & - \\
\hline \multicolumn{6}{|l|}{ Lateral dominance } \\
\hline Right-handed & 45 & 93.7 & 41 & 85.4 & \multirow[t]{2}{*}{$0.181^{\mathrm{a}}$} \\
\hline Left-handed & 03 & 6.3 & 07 & 14.6 & \\
\hline \multicolumn{6}{|l|}{ Degrees of hearing loss } \\
\hline Mild to moderate & - & - & 4 & 8.3 & - \\
\hline Severe to profound & - & - & 44 & 91.7 & \\
\hline
\end{tabular}

apearson chi-square test. 
Table 2 Occurrence of changes in head position in students with normal hearing and students with sensorineural hearing loss in the sample $(n=96)$

\begin{tabular}{|l|l|l|l|l|l|l|l|}
\hline & \multicolumn{2}{|l|}{$\begin{array}{l}\text { Normal hearing } \\
(\boldsymbol{n}=\mathbf{4 8})\end{array}$} & \multicolumn{2}{l}{$\begin{array}{l}\text { Hearing loss } \\
(\boldsymbol{n}=\mathbf{4 8})\end{array}$} & $\boldsymbol{p}$ & PR & $\mathrm{Cl}$ \\
\hline & $\boldsymbol{n}$ & $\%$ & $\boldsymbol{n}$ & $\%$ & & & \\
\hline Head position changes & 10 & 20.8 & 36 & 75 & $<0.001^{\mathrm{a}}$ & 3.26 & $1.95 ; 5.46$ \\
\hline Forward head & 7 & 14.6 & 25 & 52.1 & $<0.001^{\mathrm{a}}$ & 2.17 & $1.49 ; 3.16$ \\
\hline Lateral inclination head & 3 & 6.25 & 24 & 50 & $<0.001^{\mathrm{a}}$ & 2.56 & $1.80 ; 3.62$ \\
\hline Lateral rotation head & 1 & 2.08 & 6 & 12.5 & $0.111^{\mathrm{b}}$ & - & - \\
\hline Protruding head & 0 & 0 & 4 & 8.3 & $0.117^{\mathrm{b}}$ & - & - \\
\hline
\end{tabular}

Abbreviations: $\mathrm{Cl}$, confidence interval; $\mathrm{PR}$, prevalence ratio.

${ }^{\mathrm{a} C h i-s q u a r e ~ t e s t . ~}$

${ }^{b}$ Fisher exact test.

Table 3 Occurrence of changes in head position in students with normal hearing and students with sensorineural hearing loss, according to the gender of the sample $(n=96)$

\begin{tabular}{|c|c|c|c|c|c|c|c|c|c|c|}
\hline & \multicolumn{5}{|c|}{ Female $(n=48)$} & \multicolumn{5}{|c|}{ Male $(n=48)$} \\
\hline & \multicolumn{2}{|c|}{$\begin{array}{l}\text { Normal } \\
\text { hearing } \\
(n=24)\end{array}$} & \multicolumn{2}{|c|}{$\begin{array}{l}\text { Hearing loss } \\
(n=24)\end{array}$} & \multirow[t]{2}{*}{$p$} & \multicolumn{2}{|c|}{$\begin{array}{l}\text { Normal } \\
\text { hearing } \\
(n=24)\end{array}$} & \multicolumn{2}{|c|}{$\begin{array}{l}\text { Hearing loss } \\
(n=24)\end{array}$} & \multirow[t]{2}{*}{$p$} \\
\hline & $n$ & $\%$ & $n$ & $\%$ & & $n$ & $\%$ & $n$ & $\%$ & \\
\hline Head position changes & 5 & 20.8 & 19 & 79.2 & $<0.001^{\mathrm{a}}$ & 5 & 20.8 & 17 & 71.4 & $0.001^{\mathrm{a}}$ \\
\hline Forward head & 3 & 12.6 & 13 & 54.6 & $0.002^{\mathrm{a}}$ & 4 & 16.7 & 12 & 50 & $0.014^{\mathrm{a}}$ \\
\hline Lateral inclination head & 2 & 8.3 & 10 & 41.7 & $0.008^{b}$ & 1 & 4.2 & 14 & 58.3 & $<0.001^{\mathrm{b}}$ \\
\hline Lateral rotation head & 1 & 4.2 & 4 & 16.7 & $0.348^{\mathrm{b}}$ & 0 & 0 & 2 & 8.4 & $0.489^{b}$ \\
\hline Protruding head & 0 & 0 & 1 & 4.2 & $1.000^{\mathrm{b}}$ & 0 & 0 & 3 & 12.6 & $0.234^{\mathrm{b}}$ \\
\hline
\end{tabular}

${ }^{\mathrm{a} C h i-s q u a r e ~ t e s t . ~}$

${ }^{\mathrm{b}}$ Fisher exact test.

Postures with lateral rotation and protruding head showed no relationship with the genders, as seen in - Table 3 .

Considering the age and changes in head posture between the groups, the results showed differences only in the age group 7 to 14 years.

The changes in head posture showed differences between the age groups 7 to 10 years (normal hearing 6.3\%, hearing loss $87.5 \%, p<0.001$ ) and 11 to 14 years (normal hearing 25\%, hearing loss 93.8\%, $p<0.001$ ), as seen in - Table 4 .

Similarly, the forward head posture pointed to differences between the age group 7 to 10 years (normal hearing $0 \%$, hearing loss $50 \%, p=0.002$ ), with the same result in the group aged 11 to 14 years (normal hearing $18.8 \%$, hearing loss $75 \%, p=0.001$ ), as shown in - Table 4.

The lateral inclination posture of the head showed differences between the age groups 7 to 14 years (normal hearing $0 \%$, hearing loss $68.8 \%, p<0.001$ ) and 11 to 14 years (normal hearing $12.5 \%$, hearing loss $56.3 \%, p=0.009$ ). There was no relation between the position with head rotation and lateral protrusion of the head, as illustrated in - Table 4.

When we considered the changes in the posture in the group of children with hearing loss and the degree of hearing loss presented, we observed significant differences between the subgroups (mild/moderate $25 \%$, profound/severe $79.5 \%$, $p=0.043$ ). The results showed no differences between the specific change in head posture and the hearing loss presented, according to - Table 5.

\section{Discussion}

This study showed differences between the alignment of the head of students evaluated, and those students with hearing loss showed higher occurrence of changes in head posture compared with normally hearing students.

According to the review conducted by the authors, there are no studies evaluating the alignment of the head of students with sensorineural hearing loss and normally hearing students, and this fact hindered the expansion of the discussion of this study. However, research data reinforce the results found in this study.

Recent studies have evaluated the postural control of normally hearing children and children with hearing loss and reported that children with hearing loss showed significantly more instability in postural control than 
Table 4 Occurrence of changes in head position in students with normal hearing and students with sensorineural hearing loss, according to age group in the sample $(n=96)$

\begin{tabular}{|c|c|c|c|c|c|c|c|c|c|c|c|c|c|c|c|}
\hline & \multicolumn{4}{|c|}{$7-10$ y old $(n=32)$} & & \multicolumn{4}{|c|}{$\begin{array}{l}11-14 \text { y old } \\
(n=32)\end{array}$} & & \multicolumn{4}{|c|}{$15-18$ y old $(n=32)$} & \\
\hline & \multicolumn{2}{|c|}{$\begin{array}{l}\text { Normal } \\
\text { hearing } \\
(n=16)\end{array}$} & \multicolumn{2}{|c|}{$\begin{array}{l}\text { Hearing } \\
\text { loss } \\
(n=16)\end{array}$} & \multirow[t]{2}{*}{$p$} & \multicolumn{2}{|c|}{$\begin{array}{l}\text { Normal } \\
\text { hearing } \\
(n=16)\end{array}$} & \multicolumn{2}{|c|}{$\begin{array}{l}\text { Hearing } \\
\text { loss } \\
(n=16)\end{array}$} & \multirow[t]{2}{*}{$p$} & \multicolumn{2}{|c|}{$\begin{array}{l}\text { Normal } \\
\text { hearing } \\
(n=16)\end{array}$} & \multicolumn{2}{|c|}{$\begin{array}{l}\text { Hearing } \\
\text { loss } \\
(n=16)\end{array}$} & \multirow[t]{2}{*}{$p$} \\
\hline & $n$ & $\%$ & $n$ & $\%$ & & $n$ & $\%$ & $n$ & $\%$ & & $n$ & $\%$ & $n$ & $\%$ & \\
\hline Head position changes & 1 & 6.3 & 14 & 87.5 & $<0.001^{\mathrm{a}}$ & 4 & 25 & 15 & 93.8 & $<0.001^{\mathrm{a}}$ & 5 & 31.3 & 7 & 43.8 & $0.718^{\mathrm{a}}$ \\
\hline Forward head & 0 & 0 & 8 & 50 & $0.002^{b}$ & 3 & 18.8 & 12 & 75 & $0.001^{\mathrm{a}}$ & 4 & 25 & 7 & 31.3 & $1.000^{\mathrm{b}}$ \\
\hline Lateral inclination head & 0 & 0 & 11 & 68.8 & $<0.001^{\mathrm{a}}$ & 2 & 12.5 & 9 & 56.3 & $0.009^{a}$ & 1 & 6.3 & 4 & 25 & $0.333^{b}$ \\
\hline Lateral rotation head & 1 & 6.3 & 2 & 12.5 & $1.000^{\mathrm{b}}$ & 0 & 0 & 3 & 18.8 & $0.226^{b}$ & 0 & 0 & 1 & 6.3 & $1.000^{\mathrm{b}}$ \\
\hline Protruding head & 0 & 0 & 0 & 0 & - & 0 & 0 & 3 & 18.8 & $0.226^{\mathrm{b}}$ & 0 & 0 & 1 & 6.3 & $1.000^{b}$ \\
\hline
\end{tabular}

${ }^{\mathrm{a}}$ Chi-square test.

${ }^{b}$ Fisher exact test.

Table 5 Occurrence of changes in head position in children with sensorineural hearing loss, according to the degrees of hearing loss $(n=48)$

\begin{tabular}{|c|c|c|c|c|c|}
\hline & \multicolumn{5}{|c|}{ Degree of hearing loss $(n=48)$} \\
\hline & \multicolumn{2}{|c|}{$\begin{array}{l}\text { Mild/moderate } \\
(n=4)\end{array}$} & \multicolumn{2}{|c|}{$\begin{array}{l}\text { Severe/profound } \\
(n=44)\end{array}$} & \multirow[t]{2}{*}{$p$} \\
\hline & $n$ & $\%$ & $n$ & $\%$ & \\
\hline Head position changes & 1 & 25 & 35 & 79.5 & $0.043^{a}$ \\
\hline Forward head & 1 & 25 & 24 & 54.5 & $0.338^{\mathrm{a}}$ \\
\hline Lateral inclination head & 0 & 0 & 24 & 54.5 & $0.109^{a}$ \\
\hline Lateral rotation head & 1 & 25 & 3 & 6.8 & $0.425^{a}$ \\
\hline Protruding head & 0 & 0 & 4 & 8.3 & $1.000^{\mathrm{a}}$ \\
\hline
\end{tabular}

${ }^{\mathrm{a}}$ Fisher exact test.

normally hearing children; these instabilities could cause changes in the body posture of these children. ${ }^{13-16}$ In this context, Melo et al, who evaluated the spinal posture of 88 students ( 44 deaf and 44 normally hearing students, aged 7 to 17 years), reported that the deaf students showed significantly more postural changes in the spine when compared with normally hearing students, as observed in this study. $^{17}$

Similar to this study, Coelho-Junior et al evaluated and compared the alignment of the head of 60 subjects, 30 with normal vestibular function and 30 with unilateral vestibular hypoactivity. ${ }^{18}$ The results showed significant differences in the degrees of forward and inclination lateral head position, which were higher in patients with underactive vestibular function compared with subjects with normal vestibular function. This finding corroborates the results of this study, despite not having performed the vestibular assessment in this sample (this is a limitation of the present study, because it is an examination of relatively high cost for the study population, hardly offered public hospitals, and this research did not have sufficient funding for it to be included). However, studies have shown that children with sensorineural hearing loss often have vestibular disorders, ${ }^{19,20}$ which could cause changes in head posture in school children such as those found in this study.

The forward head posture was the most frequent postural change among schoolchildren, affecting more students with hearing loss. These data agree with Coelho-Junior et al, ${ }^{18}$ who reported that the angle of forward head posture demonstrated a higher difference between groups, affecting more students in the group with vestibular dysfunction. Sousa et al reported that the instabilities in postural control in their study occurred more commonly in the anteroposterior direction, the same direction as the forward head posture, which may explain our findings. ${ }^{13}$

The inclination head posture was the second most observed postural change in impaired schoolchildren in this study, occurring in greater proportion in the group with hearing loss. In this context, Prencht reported that individuals with hearing loss and vestibular dysfunction showed lateral inclination posture of the head, to the side of vestibular dysfunction. ${ }^{21}$ Ganança et al evaluated the posture of 82 
subjects with vestibular dysfunction and concluded that it is possible to identify postural patterns typical in these individuals. ${ }^{22}$ Among these patterns, the most noted was the inclination of the trunk and head to the same side, corroborating the results of this study.

Derlich et al reported that in their study, the instabilities in postural control of children with hearing loss occurred more commonly in the medial-lateral direction, the same direction as the lateral head posture, which could trigger such changes in head posture observed in the present study. ${ }^{14}$

Besides the data between the groups in isolation, some variables were also analyzed in this study; however, one of the most important findings was observed in the age variable. The upper age range of this study was to analyze head posture with increasing age in this population. The results demonstrated that changes in head posture occur in greater proportion in childhood and adolescence until 14 years old. Kavalco believes that these are the most critical periods for the observation of postural changes in students. ${ }^{23}$

Another important finding was observed in the subgroups of students with variable degrees of hearing loss. The students with severe to profound hearing loss had significantly increased incidence of abnormal head posture in general compared with students with mild to moderate hearing loss (-Table 5).

One explanation for this finding may be found in the study of Guilder and Hopkins, who evaluated the function of the vestibular system in children with hearing loss and reported that children with severe to profound hearing loss often had hypoactivity of the vestibular system. ${ }^{24}$ Similarly, Lavinsky stated that children with profound hearing loss showed a high incidence of vestibular dysfunction in their study. ${ }^{25}$ These data could explain the findings of this study, given that $91.5 \%$ of the children with hearing loss evaluated in this study had severe to profound loss and only $8.5 \%$ had mild to moderate loss.

According to these data, we found that children and adolescents with sensorineural hearing loss are likely to develop changes in head posture. It is believed that one of the reasons for this may be the stiffness of the neck, which might occur as an attempt to stabilize the head in a determined position to avoid vertigo and/or dizziness. ${ }^{26,27}$ This event could be associated with postural fixation of the cervical region, leading to muscle tension, pain, limitation in the amplitude joint, muscle shortening, not only in the head but reverberating throughout the body, ${ }^{28}$ which would justify the findings of this study.

Satisfactory postural control is critical to the success of most daily tasks. The knowledge of neurologic and biomechanical aspects of this control has direct implications for physical therapy, ${ }^{29}$ justifying the importance of future research to address this issue.

These data underscore the need to develop preventive and therapeutic measures in school-aged children, preventing the emergence of such changes, restoring postural pattern in students who already have asymmetries, and providing a postural pattern suitable for children with hearing loss.
The physical therapist can intervene in these disorders in childhood, with the availability of services in schools and institutions that serve this population and in multidisciplinary teams, which reinforces the importance of the presence physical therapists in the school environment. ${ }^{30}$

\section{Conclusions}

The students with sensorineural hearing loss had a higher occurrence of changes in head posture in general, compared with normally hearing students. This fact seems to affect more children and adolescents aged 7 to 14 years, of both genders and those with severe to profound hearing loss.

\section{Acknowledgments}

We thank the manager of the Gerência Regional de Educação do Agreste Centro-Norte-Caruaru, Antonio Fernando Santos Silva, for the consent to conduct the research, and the director's and the teachers of the Centre for Rehabilitation and Special Education Rotary and of School Duque de Caxias for the space given researchers to collect data. We especially thank the parents who agreed to the participation of their children in this study and students who participated.

\section{References}

1 Smith LK, Weiss EL, Lehmkuhl LD. Cinesiologia clínica de Brunnstron. 5th ed. São Paulo, Barueri, Brazil: Manole; 1997

2 Kendall FP, McCreary EK, Provance PG. Músculos: provas e funções. 4th ed. São Paulo, Brazil: Manole; 1995

3 Armstrong B, McNair P, Taylor D. Head and neck position sense. Sports Med 2008;38:101-117

4 Mangabeira Albernaz PL, Ganança MM, Caovilla HH, Ito YI, Novo NF, Juliano Y. Aspectos clínicos e terapêuticos das vertigens. Acta AWHO 1986;5(2 suppl):49-109

5 Caovilla HH, Ganança MM, Munhoz MSL, Silva MLG. Equilibriometria clínica. 1st ed. São Paulo, Brazil: Atheneu; 2000

6 Azevedo MG, Samelli AG. Estudo comparativo do equilíbrio de crianças surdas e ouvintes. Rev CEFAC 2009;11:85-91

7 Kaga K, Shinjo Y, Jin Y, Takegoshi H. Vestibular failure in children with congenital deafness. Int J Audiol 2008;47:590-599

8 Lisboa TR, Jurkiewicz AL, Zeigelboim BS, Martins-Bassetto J, Klagenberg KF. Vestibular findings in children with hearing loss. Int Arch Otorhinolaryngol 2005;9:271-279

9 Cushing SL, Papsin BC, Rutka JA, James AL, Gordon KA. Evidence of vestibular and balance dysfunction in children with profound sensorineural hearing loss using cochlear implants. Laryngoscope 2008;118:1814-1823

10 Melo RS, Silva PWA, Silva LVC, Toscano CFS. Postural evaluation of vertebral column in children and teenagers with hearing loss. Int Arch Otorhinolaryngol 2011;15:195-202

11 Kendall FP, McCreary EK, Provance PG. Músculos: provas e funções. 5th ed. São Paulo, Brazil: Manole; 2007

12 Polly DWJr, Kilkelly FX, McHale KA, Asplund LM, Mulligan M, Chang AS. Measurement of lumbar lordosis. Evaluation of intraobserver, interobserver, and technique variability. Spine 1996;21:15301535, discussion 1535-1536

13 de Sousa AM, de França Barros J, de Sousa Neto BM. Postural control in children with typical development and children with profound hearing loss. Int J Gen Med 2012;5:433-439 
14 Derlich M, Kręcisz K, Kuczyński M. Attention demand and postural control in children with hearing deficit. Res Dev Disabil 2011;32: 1808-1813

15 Sousa AMM, Barros JF, Sousa Neto BM, Gorla JI. Avaliação do controle postural e do equilíbrio em crianças com deficiência auditiva. R da Educação Física/UEM 2010;21:47-57

16 De Kegel A, Dhooge I, Cambier D, Baetens T, Palmans T, Van Waelvelde $\mathrm{H}$. Test-retest reliability of the assessment of postural stability in typically developing children and in hearing impaired children. Gait Posture 2011;33:679-685

17 Melo RS, Silva PWA, Macky CFST, Silva LVC. Análise postural da coluna vertebral: estudo comparativo entre surdos e ouvintes em idade escolar. Fisioter Mov 2012;25(4):803-810

18 Coelho-Junior NA, Gazolla JM, Gabilan YPL, Mazzetti KR, Perracini MR, Ganança FF. Alinhamento da cabeça e ombros em pacientes com hipofunção vestibular unilateral. Rev Bras Fisioter. 2010;14: 330-336

19 Schwab B, Kontorinis G. Influencing factors on the vestibular function of deaf children and adolescents: evaluation by means of dynamic posturography. The Open Otorhinolaryngology Journal 2011;5:1-9

20 Horak FB, Shumway-Cook A, Crowe TK, Black FO. Vestibular function and motor proficiency of children with impaired hearing, or with learning disability and motor impairments. Dev Med Child Neurol 1988;30:64-79

21 Prencht W. Recovery of some vestibular and vestibulospinal functions following unilateral labyrynthectomy. Prog Brain Res 1986;64:381-389
22 Ganança FF, Bushatsky A, Perracini MR, Silva D, Serafini F. Posture in patients with peripheral vestibular syndrome: exploratory study. In: Archives for Sensology and Neurootology in Science and Practice. Porto, Portugal: Neurootological and Equilibriometric Society; 2003

23 Kavalco TF. A manifestação de alterações posturais em crianças de primeira a quarta séries do ensino fundamental e sua relação com a ergonomia escolar. Rev Bras Fisioterapia 2000;2(4)

24 Guilder RP, Hopkins LA. Auditory function studies in an unselected group of pupils at the Clarke school for the deaf. Laryngoscope 1936;46:190-197

25 Lavinsky L. Vestibular function in children with severe hearing deficiency. Rev HCPA 1990;10(1):14-26

26 Horak FB, Shupert C. Função de sistema vestibular no controle postural. In: Herdman SJ, ed. Reabilitação Vestibular. São Paulo, Brazil: Manole; 2002:25-51

27 Magee DJ. Avaliação da postura. In: Magee DJ, ed. Avaliação Musculoesquelética. 3rd ed. São Paulo, Brazil: Manole; 2002: 723-753

28 Hall SJ. Biomecânica básica. Rio de Janeiro, Brazil: Guanabara Koogan; 1996

29 Shumway-Cook A, Woollacott MH. Controle postural normal. In: Shumway-Cook A, Woollacott MH, eds. Controle Motor-teoria e aplicações práticas. 2nd ed. Barueri, Brazil: Manole; 2003: 153-178

30 Melo RS, Silva PWA, Tassitano RM, Macky CFST, Silva LVC. Balance and gait evaluation: comparative study between deaf and hearing students. Rev Paul Pediatr 2012;30(3):385-391 